\title{
Instrumen Penilaian untuk Mengukur Sikap Kedisiplinan Siswa Sekolah Dasar
}

\author{
Lidya Widhaningsih ${ }^{1 *}$, Mawardi ${ }^{2}$ (ID \\ 1,2Pendidikan Guru Sekolah Dasar, Univeritas Kristen Satya Wacana, Indonesia \\ *Corresponding author: 292016116@student.uksw.edu
}

\begin{abstract}
Abstrak
Kurikulum 2013 adalah kurikulum baru yang masih digunakan hingga saat ini. Dalam kurikulum ini penilaian hasil belajar peserta didik mencakup kompetensi sikap, pengetahuan, dan ketrampilan.. penilaian sikap menjadi salah satu komponen penilaian yang penting dan harus dilakukan, akan tetapi penilaian yang dilakukan dirasa masih kurang, di zaman modern dan semakin pesatnya perkembangan teknologi semakin banyak anak-anak yang kurang memiliki sikap dislipin di sekolah maupun dirumah serta di sekolah masih banyak guru yang melakukan penilaian sikap hanya berdasarkan dari pengamatannya saja. Maka dari itu, penelitian ini bertujuan untuk menciptakan instrumen penilaian sikap untuk menilai sikap disiplin siswa kelas 2 SD. Pengembangan instrumen ini menggunakan skala Likert. Penelitian ini mengunakan jenis penelitian pengembangan R\&D. Instrumen sikap sudah melalui tahap uji validitas beberapa ahli, yaitu ahli penilaian, ahli bahasa, dan ahli pembelajaran. Uji validitas bahasa mendapatkan skor $75 \%$ sehingga masuk dalam kategori tinggi, uji validitas dari ahli penilaian sikap mendapat skor $80 \%$ sehingga masuk dalam kategori tinggi, uji validitas dari ahli pembelajaran mendapatkan skor $74,94 \%$ sehingga masuk dalam kategori tinggi. Oleh karena itu maka instrumen skala sikap unuk menilai sikap disiplin siswa kelas 2 SD ini layak untuk digunakan, serta dengan pemilhan instrumen penilain untuk mengukur sikap disiplin yang tepat dapat berpegaruh signifikan terhadap sikap disiplin siswa. Implikasi penelitian ini diharapkan dapat dapat memfasilitasi guru dan siswa dalam mengukur kemampuan afektif khususnya sikap disiplin agar tujuan pendidikan lebih mudah tercapai.
\end{abstract}

Kata kunci: Instrumen Penilaian Sikap, Kedisiplinan

\section{Abstract}

The 2013 curriculum is a new curriculum that is still used today. In this curriculum, the assessment of student learning outcomes includes the competence of attitudes, knowledge, and skills. Attitude assessment is one of the important components of assessment and must be carried out, but the assessment carried out is felt to be lacking, in modern times and the rapid development of technology more and more children who lack discipline at school and at home as well as at school there are still many teachers who conduct attitude assessments only based on their observations. Therefore, this study aims to create an attitude assessment instrument to assess the discipline attitude of 2 nd grade elementary school students. The development of this instrument uses a Likert scale. This research uses the type of $R \& D$ development research. The attitude instrument has gone through the stage of testing the validity of several experts, namely assessment experts, linguists, and learning experts. The language validity test got a score of $75 \%$ so it was in the high category, the validity test from the attitude assessment expert got a score of $80 \%$ so it was in the high category, the validity test from the learning expert got a score of $74.94 \%$ so it was in the high category. Therefore, the attitude scale instrument to assess the discipline attitude of grade 2 elementary school students is feasible to use, and the selection of an assessment instrument to measure the appropriate discipline attitude can have a significant effect on student discipline attitudes. The implications of this research are expected to be able to facilitate teachers and students in measuring affective abilities, especially discipline attitudes so that educational goals are more easily achieved.

Keywords: Attitude Assessment Instruments, Discipline

\section{INTRODUCTION}

Penilaian hasil belajar dilakukan sebagai tolak ukur dalam suatu kegiatan pembelajaran. Penilaian merupakan suatu proses untuk mengetahui (menguji) apakah suatu kegiatan, proses kegiatan, keluaran suatu program telah sesuai dengan tujuan atau kriteria yang telah ditentukan (Candra et al., 2018; Wicaksono et al., 2016a). Hasil belajar yang telah diperoleh setiap peserta didik dapat digunakan sebagai salah satu sarana untuk menilai kualitas pembelajaran yang dilakukan serta sebagai umpan balik untuk kegiatan pembelajaran selanjutnya (Agustina, 2015; Hanida et al., 2019). Penilaian mencakup kompetensi sikap,

$\begin{array}{ll}\text { History: } & \\ \text { Received } & \text { : June 01, 2021 } \\ \text { Revised } & \text { : June 09, 2021 } \\ \text { Accepted } & \text { : October 10, 2021 } \\ \text { Published } & \text { : November 25, } 2021\end{array}$


pengetahuan, dan ketrampilan harus dilakukan secara berimbang sehingga dapat digunakan untuk menentukan posisi relatif setiap peserta didik terhadap standar yang telah ditetapkan (Novika Auliyana et al., 2018; Subagia \& Wiratma, 2016; Wicaksono et al., 2016a). Kegunaan utama penilaian sikap sebagai bagian dari pembelajaran adalah refleksi (cerminan) pemahaman dan kemajuan sikap peserta didik secara individual (Haryanti \& Saputra, 2019; Novika Auliyana et al., 2018). Penilaian hasil belajar pada pendidikan dasar dan pendidikan menengah, tujuan penilaian adalah mengetahui tingkat penguasaan kompetensi dalam sikap, pengetahuan, dan keterampilan yang sudah dan belum dikuasai seorang/sekelompok peserta didik untuk ditingkatkan dalam pembelajaran remedial dan pengayaan(Novika Auliyana et al., 2018; Wulandari \& Radia, 2021). Menetapkan program perbaikan atau pengayaan berdasarkan tingkat penguasaan kompetensi bagi mereka yang diidentifikasi sebagai peserta didik yang lambat atau cepat dalam belajar dan pencapaian hasil belajar(Prasetya, 2012; Utami \& Wardani, 2020). Menetapkan ketuntasan penguasaan kompetensi belajar peserta didik ditetapkan harian, satu semesteran, satu tahunan, dan masa studi satuan pendidikan., Memperbaiki proses pembelajaran pada pertemuan dan/atau semester berikutnya dan memetakan mutu satuan pendidikan.

Namun, kenyataan saat ini banyak sekali permasalahan yang timbul di Indonesia, salah satunya kurangnya kepedulian masyarakat terhadap lingkungan. Faktor tersebut terjadi karena manusia tidak disiplin untuk menjaga lingkungan sekitar (Amma et al., 2020; Oktavia \& Mulabbiyah, 2019). Sering dijumpai juga bahwa siswa tidak disiplin ketika berada di lingkungan sekolah dan rumah. Berdasarkan pengamatan yang dilakukan di Sekolah Dasar yang berada di Kota Salatiga, masih terdapat beberapa siswa yang perlu diingatkan agar mereka membuang sampah di tempat sampah. Sikap disiplin untuk menjaga dan merawat lingkungan perlu ditanamkan kepada siswa. Disiplin merupakan kegiatan yang dilakukan oleh setiap siswa untuk melakukan sesuatu secara teratur dan tertib serta penuh tanggung jawab sesuai dengan peraturan yang berlaku (Handayani \& Subakti, 2020; Saputro \& Pardiman, 2012). Hasil observasi dan wawancara yang di lakukan pada guru SD Negeri Kapuhan 1 dan SD Negeri Kapuhan 2 menyatakan bahwa guru masih kurang dalam melakukan penilaian sikap. Hasil belajar siswa sudah ada penilaian sikap, namun hasil penilaian diperoleh dari hasil pengamatan saja. Penilaian sikap disiplin juga masih kurang dalam penilaiannya. Jika permasalahan tersebut dibiarkan, maka akan berpengaruh terhadap kualitas sumber daya manusia. Oleh karena itu penilaian guru masih memerlukan alat untuk menilai sikap terutama sikap kedisiplinan.

Solusi yang dapat dilakukan untuk mengatasi permasalahan tersebut, guru perlu menggunakan instrument penilaian sikap dalam mengukur keterampilan afektif siswa. Dalam menilai sikap disiplin yang dilakukan oleh siswa, guru perlu menggunakan indikator indikator penilaian sikap disiplin (Nufus et al., 2017; Wicaksono et al., 2016a). Sikap disiplin dapat dinilai dengan mengamati kehadiran peserta didik, mengikuti peraturan yang da di sekolah, dll (Wicaksono et al., 2016b). Namun sebaiknya guru perlu mengembangkan indikator indikator penilaian sikap disiplin sesuai dengan keaadaan yang ada di sekolah atau sesuai dengan materi yang dipelajari oleh siswa. Guru harus mampu menyiapkan atau membuat alat untuk mengukur sikap terutama sikap kedisipinan siswa dengan benar, bukan dengan pengamatan saja. Alat untuk mengukur harus teruji kelayakannya baik dari aspek bahasa, aspek penilaian dan aspek pembelajarannya. Oleh karena itu perlu adanya pengembangan skala sikap untuk mengukur sikap pada peserta didik terutama sikap kedisiplinannya. Tujuan pengembangan ini adalah untuk membantu atau memudahkan guru dalam melakukan penilaian sikap kedisiplinan peserta didik kelas 2 SD. Tentunya skala sikap yang tepat dan sudah teruji kelayakannya baik aspek bahasa, aspek penilaian dan aspek pembelajaran yang tinggi.

Beberapa temuan penelitian sebelumnya menyatakan instrumen penilaian sikap ilmiah yang dikembangkan dijadikan solusi dan dapat dijadikan alternatif bagi guru dalam melakukan 
proses penilaian sikap ilmiah (Suryani, 2016; Wicaksono et al., 2016a). Pengembangan instrumen penilaian sikap ini hendaknya dapat terus dilaksanakan mengingat kemajuan tuntutan pendidikan kedepannya (Candra et al., 2018; Simarmata et al., 2019). Penting dilakukan pengembangan penilaian sikap untuk mengetahui sikap siswa terhadap mata pelajaran IPA(Irwan et al., 2018; Purnomo \& Wilujeng, 2016). Tujuan penelitian ini adalah untuk menciptakan produk berupa instrumen penilaian sikap disiplin dengan menggunakan Skala Likert dalam pembelajaran tematik kedisiplinan siswa kelas 2 SD pada pembelajaran tematik Tema 3 Tugas Sehari-hari Subtema 4 "Tugasku Sehari-hari di Lingkungan Sosial serta untuk mengetahui tingkat validitas dan kelayakan instrumen yang dihasilkan. Produk instrumen penilaian sikap disiplin dapat digunakan untuk mempermudah guru dalam menilai sikap disiplin siswa kelas II SD.

\section{MATERIALS AND METHODS}

Jenis penelitian ini merupakan jenis pengembangan atau penelitian R\&D (Sugiono, 2018). Produk yang akan dikembangkan adalah instrumen penilaian sikap untuk mengukur sikap kedisiplinan siswa kelas 2 SD menggunakan Skala Likert. Penilaian sikap kedisiplinan ini untuk kelas 2 dengan pembelajaran tematik pada Tema 3 "Tugas Sehari-hari” Subtema 4 "Tugas di Lingkungan Sosial". Pembelajaran 4. Penelitian dan pengembangan ini menggunakan langkah-langkah yang diadopsi dari sepuluh langkah penelitian pengembangan Borg, Gall \& Gall (2007: 589), yang merupakan edisi revisi dari Borg and Gall and Gall (2003 : 570). Langkah langkah penelitian dan pengembangan yang dilakukan untuk menghasilkan produk tertentu untuk menguji keaktifan produk yang dimaksud yaitu, research and Information Collection, Planning Develop Preliminary form of product, dan Preliminary Field Testing, Main product revision, Main field testing, Operational product revision, Operational field testing, Final product revision, Dissemination and implementation. Namun karena situasi pandemi Covid-19 ini tidak memungkinkan peneliti untuk melakukan semua langkah-langkah diatas. Peneliti hanya melakukan penelitian hingga langkah ke-4. Pengumpulan data dengan menggunakan teknik observasi, wawancara dan angket (instrumen validasi ahli). Dalam penelitian ini, alat yang digunakan adalah instrumen non tes. Teknik non tes merupakan alat penilaian yang dipergunakan untuk mendapatkan informasi tentang keadaan peserta didik atau peserta tes tanpa melalui tes dengan alat tes (Ariani, 2020; Suryani, 2016). Teknik non tes memegang peranan penting dalam rangka mengevaluasi hasil belajar peserta didik dari segi ranah sikap hidup (affectif domain). Uji validasi dilakukan dengan tiga ahli, yaitu ahli bahasa, ahli penilaian sikap dan ahli pembelajaran. Angket validasi bahasa disusun berdasarkan 6 aspek yaitu lugas, komunikatif, dialogis dan interaktif, kesesuaian dengan perkembangan siswa, kesesuaian dengan kaidah Bahasa Indonesia, dan penggunaan istilah, simbol, dan ikon. Kemudian angket validasi penilaian sikap ini didasarkan pada rambu-rambu penyusunan pernyataan sikap menurut Azwar. Sedangkan angket validasi pembelajaran sesuai dengan Permendikbud No. 22 tahun 2016. Teknik yang digunakan dalam penelitian ini adalah teknik analisis dan kualitatif berupa presentase.

\section{RESULTS AND DISCUSSION}

\section{Results}

Penelitian pengembangan instrumen penilaian sikap untuk mengukur sikap kedisiplinan siswa kelas 2 SD menggunakan langkah-langkah yang diadopsi dari Borg and Gall and Gall. Studi pendahuluan, tujuan studi pendahuluan adalah untuk mendeskripsikan skala sikap, sikap yang ditentukan dan kebutuhan skala sikap untuk memudahkan guru dalam menilai sikap kedisiplinan siswa. Kegiatan yang dilakukan untuk mencapai tujuan tersebut 
adalah melakukan studi pustaka dan penelitian skala kecil. Pengembangan instrument dengan menggunakan langkah-langkah menurut Borg and Gall and Gall. Pertama, Research and Information Collection. Tahap ini adalah tahap awal yang dilakukan dengan melakukan observasi dan wawancara pada SDN Kapuhan 1 dan SDN Kapuhan 2 di Kecamatan Sawangan, Kabupaten Magelang. Hasil wawancara dan observasi menunjukan bahwa selama ini sekolah kurang memperhatikan penilaian sikap, terutama sikap kedisiplinan siswa. Ada penilaian sikap namun hanya berdasarkan pengamatan saja. Pengukuran kebutuhan yang digunakan sebagai dasar dalam pelaksanaan penelitian ini untuk mengembangkan instrumen penilaian sikap untuk mengukur sikap kedisiplinan siswa kelas 2 SD pada pembelajaran tematik Tema 3 "Tugas Sehari-hari" Subtema 4 "Tugasku Sehari-hari di Lingkungan Sosial”.

Kedua, planning atau perencanaan. Pemilihan tema 3 "Tugas Sehari-hari" Sub tema 4 "Tugasku Sehari-hari di Lingkungan Sosial" karena pada Tema 3 ini aspek sikap yang dikembangkan dalam pembelajarannya adalah sikap disiplin sesuai dengan aspek sikap yang akan dikembangkan oleh peneliti. Penelitian ini berfokus pada pengembangan sikap disiplin seperti yang terdapat pada Kompetensi Inti 2 (KI-2). Kompetensi Dasar (KD) yang digunakan oleh peneliti adalah Kompetensi Dasar 2 (KD-2), KD 2.1 yaitu "Bersikap bekerja sama,disiplin,dan peduli sesuai dengan sila-sila Pancasila dalam lambang Negara "Garuda Pancasila"dalam kehidupan sehari-hari." Dari KD di atas maka dapat dikembangkan beberapa indikator pembelajaran. Dari indikator kemudian dapat dikembangkan tujuan pembelajaran yang digunakan sebagai dasar untuk menyusun Rencana Pelaksanaan Pembelajaran (RPP). Berikut adalah kisi-kisi instrumen penilaian sikap untuk mengukur sikap kedisiplinan siswa kelas 2 SD pada Tabel 1.

Tabel 1. Kisi-kisi Insrumen Penilian Sikap

\begin{tabular}{|c|c|c|c|c|c|}
\hline \multirow{2}{*}{$\begin{array}{l}\text { Komponen indikat } \\
\text { obyek sikap }\end{array}$} & \multicolumn{3}{|c|}{ Komonen Sikap } & \multirow{2}{*}{ Jumlah } & \multirow{2}{*}{$(\%)$} \\
\hline & Kognisi & Afeksi & Konasi & & \\
\hline Hakikat disiplin sekolah & 4 & 0 & 0 & 4 & 14 \\
\hline Tujuan disiplin sekolah & 2 & 2 & 1 & 5 & 14 \\
\hline Seragam sekolah & 1 & 2 & 2 & 5 & 16 \\
\hline Jam sekolah & 1 & 2 & 2 & 5 & 16 \\
\hline Cara berperilaku & 1 & 2 & 3 & 6 & 20 \\
\hline Etika belajar & 1 & 2 & 2 & 5 & 16 \\
\hline Total & 10 & 10 & 10 & 30 & 100 \\
\hline
\end{tabular}

Tahap ketiga develop preliminary form of product atau pengembangan draf produk awal. Pada tahap ini menyusun materi yaitu materi dari Tema 3 "Tugas Sehari-hari" Sub tema 4 “Tugasku Sehari-hari di Lingkungan Sosial” pada pembelajaran ke-4. Mata Pelajaran yang ada pada pembelajaran ini adalah Bahasa Indonesia, PPKn, dan Matematika. Tahap ketiga preliminary field testing atau uji coba lapangan awal. Pada tahap ini pembuatan instrumen penilaian sikap berupa butir-butir pernyataan mengenai kedisiplinan dengan Skala Likert berdasarkan obyek sikap, batasan dan tujuan, serta indikator yang sudah ditentukan. Peneliti menyusun 30 butir pernyataan untuk mengukur sikap kedisiplinan siswa kelas 2 SD. 10 pernyataan kognisi, 10 pernyataan afeksi, dan 10 pernyataan konasi. Selanjutnya penelii melaksanakan uji kelayakan kepada tiga ahli, yaitu ahli bahasa, ahli penilaia sikap, dan ahli pembelajaran. Hasil uji validasi dari ketiga aspek pada Tabel 2.

Tabel 2 menunjukkan bahwa hasil validasi aspek bahasa memperoleh presentase kelayakan sebesar $72 \%$ dengan kategori tinggi dan layak untuk digunakan. Hasil dari validasi ahli bahasa mendapatkan skors $75 \%$, dari skors tersebut maka termasuk dalam interval $61-81 \%$ sehingga dikategorikan dalam kategori "Tinggi" setelah melalui proses perbaikan. Hasil dari 
validasi ahli penilaian sikap mendapatkan skor $80 \%$, dari skor tersebut maka termasuk dalam interval 61-81 \% sehingga dikategorikan dalam kategori "Tinggi". Hasil uji validasi aspek pembelajaran mendapatkan skor $72,94 \%$, dari skor tersebut termasuk ke dalam interval 6180\% sehingga dikategorikan ke dalam kategori "Tinggi". Instrumen ini sudah melalui proses parbaikan, oleh karena itu produk ini sudah layak untuk digunakan. Pada tahap pengujian ini seharusnya dilakukan kegiatan pre test sebelum produk diberikan kepada siswa dan post test setelah produk diberikan kepada siswa untuk analisis statistikuji perbedaan. Namun karena situasi pandemi Covid-19 maka pengujian tidak dapat dilaksanakan. Valid berarti instrumen dapat digunakan untuk mengukur apa yang seharusnya diukur. Berdasarkan beberapa masukan saran yang diberikan oleh tim ahli terhadap instrumen penilaian sikap disiplin tersebut telah lolos penilaian kelayakannya.

Tabel 2. Hasil uji Validasi Aspek Bahasa

\begin{tabular}{lcc}
\hline \multicolumn{1}{c}{ Aspek } & Persentase Kelayakan & Kategori \\
\hline Aspek Bahasa & $72 \%$ & Tinggi \\
Aspek Penilaian Sikap & $80 \%$ & Tinggi \\
Aspek Desain Pembelajaran & $75,38 \%$ & Tinggi \\
\hline
\end{tabular}

\section{Discussion}

Berdasarkan hasil penelitian, instrument penilaian untuk mengukur sikap kedisiplinan siswa kelas dua sekolah dasar layak diterapka di sekolah dasar. Hal ini dapat dilihat dari beberapa aspek. Pertama, validasi instrument ini didasarkan pada rambu-rambu penyusunan pernyataan sikap. Pernyataan yang dimaksud pernyataan tidak mengandung unsur masalalu, pernyataan tidak mengandung unsur fakta atau dapat diterjemahkan menjadi sebuah fakta, pernyataan tidak memiliki penafsiran lebih dari satu, pernyataan tidak keluar dari objek psikologis yang hendak diukur, pernyataan tidak mengundang reaksi persetujuan dari semua pihak atau sebaliknya, memilih pernyataan yang mencakup rentang afektif yang diinginkan, pernyataan ditulis menggunakan bahasa yang sederhana, jelas, dan langsung. Pengembangan tes yang baik memerlukan beberapa persyaratan. Tes yang baik harus memenuhi setidaknya dua karakteristik, yaitu: validitas dan reliabilitas (Andriani et al., 2019; Pratiwi \& Fasha, 2015). Kedua aspek bahasa, pada instrument menggunakan bahasa yang ringkas dan tidak lebih dari 20 kata, pernyataan hanya mengandung satu ide atau gagasan, pernyataan tidak mengandung unsur universal, pernyataan menghindari penggunaan kata hanya, sekedar, semata-mata, dan kata lain sebagainya yang memiliki arti yang sama dengan kata tersebut, pernyataan sebisa mungkin disusun menggunakan kata-kata yang sederhana, pernyataan tidak menggunakan kata-kata yang sulit untuk dipahami, pernyataan tidak menggunakan kata-kata negatif ganda. Bahasa yang sederhana akan memudahkan siswa untuk memahami pernyataan dari instrument (Pratiwi \& Fasha, 2015; Wicaksono et al., 2016a). oleh karena itu instrument penilaian ini layak digunakan untuk mengukur sikap disiplin siswa. Ketiga, desain pembelajaran dari produk instrumen penilaian sikap untuk mengukur sikap kedisiplinan siswa kelas 2 SD. Validasi ahli desain pembelajaran ini sesuai dengan Permendikbud No. 22 tahun 2016. Kelayakan desain pembelakaran dilihar dari aspek komponen pembelajaran dan prinsip pembelajaran. Komponen pembelajaran diantaranya adalah identitas sekolah, identitas mata pelajaran, kelas dan semester, materi pokok pembelajaran, alokasi waktu pembelajaran, tujuan pembelajaran, kompetensi dasar dan indikator, materi pembelajaran, metode pembelajaran, media pembelajaran, sumber belajar, langkah-langkah pembelajaran, dan penilaian hasil pembelajaran. Prinsip pembelajaran diantaranya keaktifan siswa dalam pembelajaran, keterlibatan siswa dalam pembelajaran, kejelasan umpan balik, dan keterpaduan pembelajaran 
(Jiemsak \& Jiemsak, 2020). Instrumen ini sudah melalui prroses perbaikan yang dilakukan oleh peneliti, oleh karena itu instrumen ini "layak digunakan".

Temuan ini diperkuat dengan penelitian sebelumnya menyatakan instrument penilaian sikar penting untuk dikembangkan (Candra et al., 2018; Simarmata et al., 2019). Instrument penilaian sikap layak digunakan pada pembelajaran karena sudah melalui uji validitas (Dessiane \& Kristin, 2021; Wulandari \& Radia, 2021). Instrumen penilaian sikap disiplin layak diterapkan pada proses pembelajaran (Pratiwi \& Fasha, 2015). Dari pembahasan tersebut instrumen penilaian digunakan sebagai bahan evaluasi dan mengukur kemampuan perserta didik. Evaluasi merupakan salah satu bagian yang penting dalam kegiatan pembelajaran. Evaluasi tidak hanya dilakukan dengan cara tes, karena evaluasi dengan menggunakan tes hanya dapat digunakan untuk mengukur ranah kognitif saja. Sedangkan dalam pembelajaran harus dilakukan penilaian ranah afektif dan psikomotorik (Krissandi \& Rusmawan, 2015; Utami \& Wardani, 2020; Widiana, 2016). Pada pembelajaran di SD, penilaian yang dilakukan oleh guru adalah dari aspek kognitif dan afektif. Di SDNKapuhan 1 dan SDN Kapuhan 2, penilaian kognitif dilakukan dengan menggunakan tes, sedangkan penilaian afektif dilakukan dengan pengamatan sehari-hari. Cara penilaian dengan melakukan pengamatan sebenarnya tidak salah, akan tetapi cara ini kurang relevan untuk menilai afektif. Dengan cara ini, guru hanya akan menggeneralisasikan penilaiannya terhadap semua siswa, jadi setiap siswa memiliki nilai afektif yang sama. Oleh karena itu untuk mengetahui nilai afektif yang sebenarnya dari siswa, peneliti melakukan pengembangan instrumen penilaian sikap khususnya sikap disiplin untuk siswa SD dengan teknik non tes menggunakan Skala Likert sebagai alat untuk menilai afektif siswa. Penilaian menggunakan penilaian non-tes dirasa lebih relevan.

\section{CONCLUSION}

Pengembangan instrumen penilaian sikap disiplin dalam pembelajaran tematik kelas dua SD menggunakan Skala Lickert layak digunakan untuk menilai sikap disiplin siswa kelas dua SD pada tema tiga "Tugas Sehari-hari" Sub tema empat "Tugasku Sehari-hari di Lingkungan Sosial"..Produk instrumen penilaian sikap menggunakan skala Likert dalam pembelajaran tematik kelas dua SD sangat layak digunakan. Implikasi penelitian ini diharapkan dapat dapat memfasilitasi guru dan siswa dalam mengukur kemampuan afektif khususnya sikap disiplin agar tujuan pendidikan lebih mudah tercapai.

\section{REFERENCES}

Agustina, R. L. (2015). Upaya Meningkatkan Hasil Belajar IPA Siswa Kelas IV Menggunakan Model STAD dan NHT. Journal of Educational Science and Technology (EST), 1 (3). https://doi.org/10.26858/est.v1i3.1801.

Amma, T., As, E., Syaikhoni, Y., \& Karakter, I. (2020). Implementasi Karakter Disiplin Peserta Didik Melalui Kerjasama Sekolah Dan Orang Tua. QUDWATUNA, 3(2), 101123. http://ejournal.alkhoziny.ac.id/index.php/qudwatuna/article/view/99.

Andriani, A., Dewi, I., \& Sagala, P. N. (2019). Development of blended learning media using the mentimeter application to improve mathematics creative thinking skills. Journal of Physics: Conference Series, 1188(1), 12112. https://doi.org/10.1088/17426596/1188/1/012112.

Ariani, T. (2020). Analysis of Students' Critical Thinking Skills in Physics Problems. Physics Educational Journal, 3(1), 1-13. https://doi.org/10.37891/kpej.v3i1.119.

Candra, I., Sulistya, N., \& Prasetyo, T. (2018). Pengembangan Instrumen Sikap Sosial Tematik Siswa SD Kelas IV. Jurnal Ilmiah Sekolah Dasar, 2(4), 455. 
https://doi.org/10.23887/jisd.v2i4.16167.

Dessiane, S. T., \& Kristin, F. (2021). Pengembangan Instrumen Penilaian Sikap Sosialpembelajaran Tematik Kelas 4 SD. Jurnal Pendidikan Ilmu Pengetahuan Sosial Indonesia, 6(1), 21-26. https://doi.org/10.26737/jpipsi.v6i1.2310.

Handayani, E. S., \& Subakti, H. (2020). Pengaruh Disiplin Belajar terhadap Hasil Belajar Bahasa Indonesia di Sekolah Dasar. Jurnal Basicedu, 5(1), 151-164. https://doi.org/10.31004/basicedu.v5i1.633.

Hanida, Neviyarni, \& Fahrudin, F. (2019). Peningkatan Hasil Belajar Siswa Menggunakan Bahan Ajar Tematik Terpadu Berbasis Model Discovery Learning Di Kelas IV Sekolah Dasar. Jurna Basicedu, 3(2), 716 - 724. https://doi.org/10.31004/basicedu.v3i2.60.

Haryanti, Y. D., \& Saputra, D. S. (2019). Instrumen Penilaian Berpikir Kreatif Pada Pendidikan Abad 21. Jurnal Cakrawala Pendas, 5(2). https://doi.org/10.31949/jcp.v5i2.1350.

Irwan, A., Arsyad, M., \& Arafah, K. (2018). Pengembangan Instrumen Penilaian Sikap Praktikum Fisika Dasar I Pada Mahasiswa Jurusan Pendidikan Fisika Uin Alauddin Makassar. JPFT (Jurnal Pendidikan Fisika Tadulako Online), 4(2), 168 - 175. https://doi.org/10.29303/jpft.v4i2.763.

Jiemsak, N., \& Jiemsak, R. (2020). The effectiveness of the quizizz interactive quiz media as an online self-assessment of undergraduate students to improve students' learning outcomes. 2020 5th International STEM Education Conference, ISTEM-Ed 2020, 1567(2), 51-54. https://doi.org/10.1109/iSTEM-Ed50324.2020.9332675.

Krissandi, A. D. S., \& Rusmawan, R. (2015). Kendala Guru Sekolah Dasar Dalam Implementasi Kurikulum 2013. Jurnal Cakrawala Pendidikan, 3(3), 457-467. https://doi.org/10.21831/cp.v3i3.7409.

Novika Auliyana, S., Akbar, S., \& Yuniastuti. (2018). Penerapan Pembelajaran Tematik Terpadu di Sekolah Dasar. Jurnal Pendidikan: Teori, Penelitian, Dan Pengembangan, 3(12), 1572-1582. https://doi.org/10.17977/jptpp.v3i12.11796.

Nufus, S. H., Gani, A., \& Suhendrayatna, S. (2017). Pengembangan Instrumen Penilaian Sikap Berbasis Kurikulum 2013 Pada Pembelajaran Kimia SMA. Jurnal Pendidikan Sains Indonesia (Indonesian Journal of Science Education), 5(1), 44-51. http://202.4.186.66/JPSI/article/view/8406.

Oktavia, N., \& Mulabbiyah, M. (2019). Gawai Dan Kompetensi Sikap Sosial Siswa Mi (Studi Kasus Pada Siswa Kelas V Min 2 Kota Mataram). El Midad, 11(1), 19-40. https://doi.org/10.20414/elmidad.v11i1.1903.

Prasetya, T. I. (2012). Meningkkatkan Keterampilan Menyusun Instrumen Hasil Belajar Berbasis Modul Interaktif Bagi Guru-guru IPA SMP N Kota Malang. Journal of Educational Research and Evaluation, 1(2).

Pratiwi, U., \& Fasha, E. F. (2015). Pengembangan Instrumen Penilaian HOTS Berbasis Kurikulum 2013 Terhadap Sikap Disiplin. Jurnal Penelitian Dan Pembelajaran IPA, 1(1), 123 - 142. https://jurnal.untirta.ac.id/index.php/JPPI/article/view/330/230.

Purnomo, H., \& Wilujeng, I. (2016). Pengembangan bahan ajar dan instrumen penilaian IPA tema Indahnya Negeriku penyempurnaan buku guru dan siswa kurikulum 2013. Jurnal Prima Edukasia, 4(1), 67-78. https://doi.org/10.21831/jpe.v4i1.7697.

Saputro, S. T., \& Pardiman, P. (2012). Pengaruh Disiplin Belajar Dan Lingkungan Teman Sebaya Terhadap Prestasi Belajar Mahasiswa Program Studi Pendidikan Akuntansi Angkatan 2009 Fakultas Ekonomi Universitas Negeri Yogyakarta. Jurnal Pendidikan Akuntansi Indonesia, 10(1), 78-97. https://doi.org/10.21831/jpai.v10i1.923.

Simarmata, N. N., Wardani, N. S., \& Prasetyo, T. (2019). Pengembangan Instrumen Penilaian Sikap Toleransi dalam Pembelajaran Tematik Siswa Kelas IV SD. Jurnal Basicedu, 3(1), 194 - 199. https://doi.org/10.31004/basicedu.v3i1.101.

Subagia, I. W., \& Wiratma, I. G. L. (2016). Profil Penilaian Hasil Belajar Siswa Berdasarkan 
Kurikulum 2013. JPI (Jurnal Pendidikan Indonesia), 5(1), 39-54. https://doi.org/10.23887/jpi-undiksha.v5i1.8293.

Sugiono. (2018). Metode Penelitian Pendididkan Pendekatan Kuantitatif, Kualitatif, dan $R \& D$. Alfabeta.

Suryani, I. (2016). Pengembangan instrumen penilaian sikap ilmiah pada pembelajaran dengan model latihan penelitian di sekolah dasar. PEDADIDAKTIKA: Jurnal Ilmiah Pendidikan Guru Sekolah Dasar, 3(2), 217-227. https://ejournal.upi.edu/index.php/pedadidaktika/article/view/5152.

Utami, D. A. P., \& Wardani, N. S. (2020). Pengembangan Instrumen Penilaian Kognitif dalam Pembelajaran Tematik Kelas 5 SD. Jurnal Ilmiah Kependidikan, 20(2), 1-18. https://doi.org/10.12345/lentera.v12i2.463.

Wicaksono, T. P., Muhardjito, \& Harsiati, T. (2016a). Pengembangan penilaian sikap dengan teknik observasi, self assessment, dan peer assessment pada pembelajaran tematik kelas V SDN Arjowinangun 02 Malang. Jurnal Pendidikan: Teori, Penelitian, Dan Pengembangan, 1(1), 45-51. https://doi.org/10.17977/jp.v1i2.5214.

Wicaksono, T. P., Muhardjito, \& Harsiati, T. (2016b). Pengembangan Penilaian Sikap dengan Teknik Observasi Self Assessment, dan Peer Assessment pada Pembelajaran Tematik Kelas V SD N Arjowinangun 02 Malang. Jurnal Pendidikan - Teori, Penelitian, Dan Pengembangan, 1(2), 45 - 51. https://doi.org/10.17977/jp.v1i2.5214.

Widiana, I. W. (2016). Pengembangan Asesmen Proyek Dalam Pembelajaran IPA di Sekolah Dasar. JPI (Jurnal Pendidikan Indonesia), 5(2), 147. https://doi.org/10.23887/jpiundiksha.v5i2.8154.

Wulandari, A. I., \& Radia, E. H. (2021). Pengembangan Instrumen Penilaian Sikap Tanggung Jawab Pembelajaran Tematik Terpadu Kelas V SD. MIMBAR PGSD Undiksha, 9(1), 10-18. https://doi.org/10.23887/jjpgsd.v9i1.32979. 